\title{
Effect of Washed Sunflower Oil on Lipid Profile in the Experimental Hypercholesterolemia in the Adult Male Rats
}

\author{
Man S. Kalo \\ Department of physiology, biochemistry and pharmacology \\ College of veterinary medicine \\ University of Mosul
}

\section{Received \\ $16 / 09 / 2007$ \\ Accepted \\ 03 / 03 / 2008}

\section{الخلاصة}

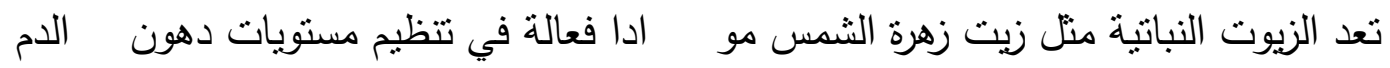

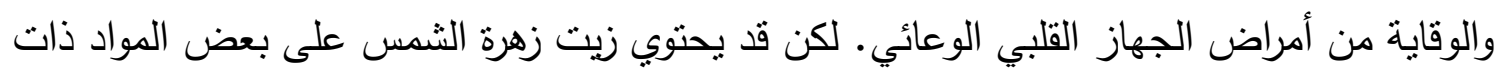

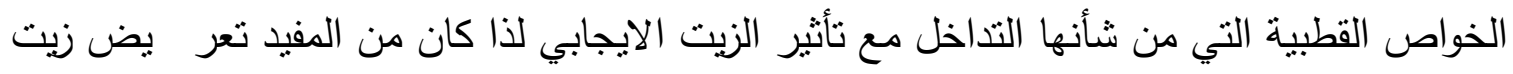

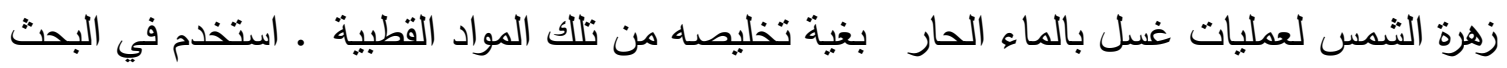

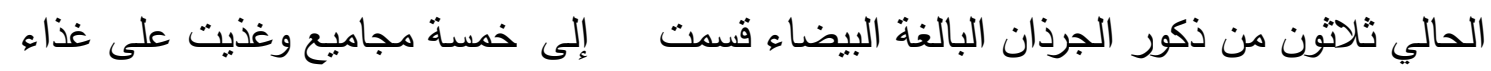

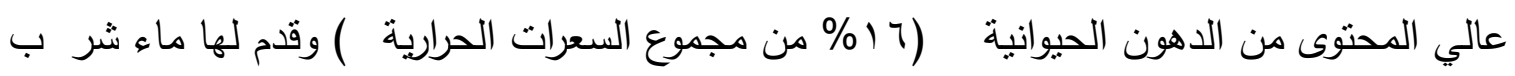

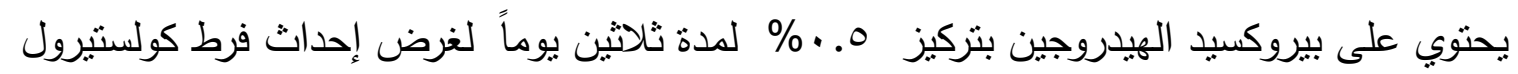

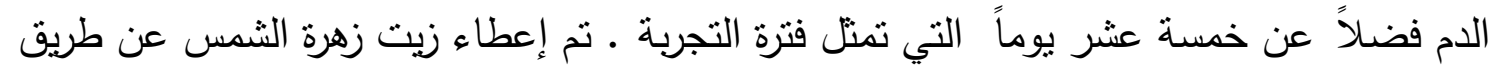

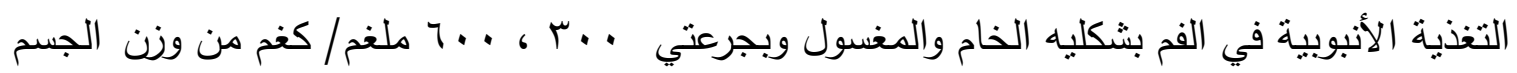

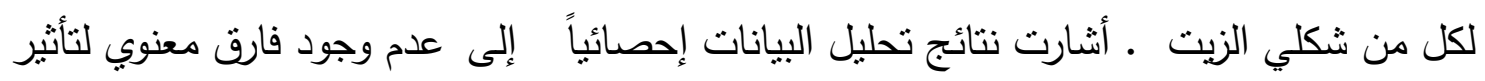

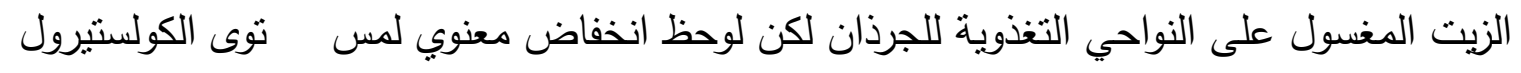

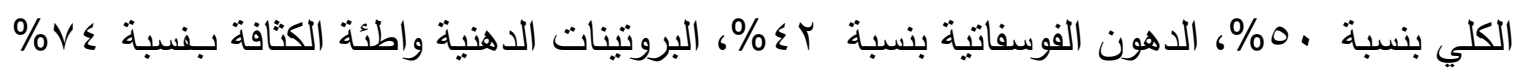

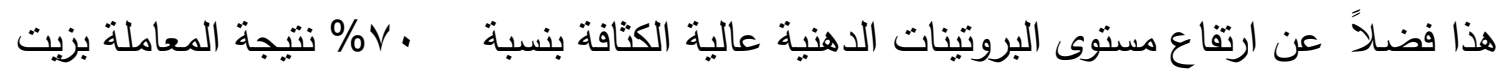

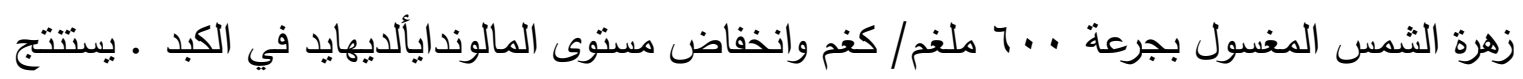

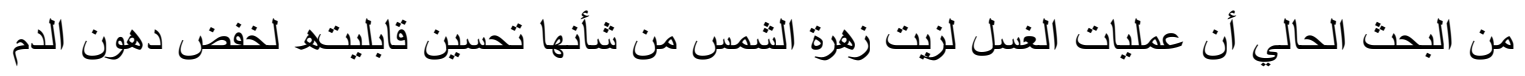

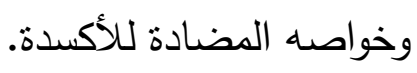




\begin{abstract}
Vegetable oils are considered to be active in modulation of the blood lipid profile and profilacting from cardiovascular diseases, oils extracted from plants (sunflower seeds) may also contains some polar substances which can interferes with their action, if these oils are exposed to some washing processes with worm water, these substances will be removed. A thirty adult albino male rats were divided into five groups and exposed to a hyperlipidemic and hypercholesterolemic diet (animal fats 16\% of total calories) and $\mathrm{H}_{2} \mathrm{O}_{2}(0.5 \%)$ in the water for a 30 days for induction of hypercholesterolemia in addition to 15 days in which. sunflower oil are administered orally as a crude and washed oils at a doses of 300 and $600 \mathrm{mg} /$ $\mathrm{kg}$ body weight. There was no significant effect of the washing process on the nutritional status but there were a decrease in total cholesterol TC (50 $\%$ ), phospholipids PL (42\%), low density lipoproteins LDL-c (74\%) and elevation in high density lipoproteins HDL-c (70\%) resulted from the treatment with washed oil $(600 \mathrm{mg} / \mathrm{kg}$ body weight $)$ in addition to decrease in liver malondialdehyde (MDA) content. In conclusion, the washing process of sunflower oil will improve it's hypocholesterolemic and antioxidant effects.
\end{abstract}

Key words: Sunflower oil, Rats, Cholesterol, Triglycerides, Phospholipids, Malondialdehyde.

\title{
Introduction
}

Much has been studied about the benefits of replacing animal fats with vegetable oils in the diet, "Vegetable oil" is the name usually given to any oil product derived from plants of any description (fruit, vegetable) (1).

Sunflower (Helianthus annus seeds) oil considered to be an important vegetable oil used in human nutrition. It is light in density, yellow color appearance, and low in saturated fatty acids (SFAs) (2). The ratio of polyunsaturated fatty acids (PUFAs) to Monounsaturated fatty acids (MUFAs) is about 3:1 (3). The main (PUFA) contained in Sunflower oil is linoleic acid (C18:2), while the (MUFA) is Oleic acid (C18:1) (about 25\%) whereas the palmitic acid $(\mathrm{C} 16: 0)$ is the major SFA $(6 \%)(3)$.

The consumption of (PUFAs) and (MUFAs) in place of SFAs may lower the risk of atherosclerosis and lowering the mortality due to heart disease by reducing cholesterol levels in the blood $(\mathbf{4 , 5})$, in addition to the sunflower oil fat soluble vitamins content especially E and A which they are considered a powerful antioxidants (6), Phytosterols are also found in sunflower oil and they are effective because of their cholesterol lowering and antioxidant capacity (4), Sunflower oil has an iodine value about 130 and peroxide value about $0.5 \mathrm{meq} / \mathrm{kg}$ and specific gravity at $25 \stackrel{\mathrm{C}}{\mathrm{C}}$ is about 0.92 according to some national normal values (3). 
Although the beneficial effect of the vegetable oils on the lipid metabolism and lipid peroxidation $(\mathbf{4 , 7})$, but there is an evidence that mechanical washing processes could be applied on these oils, It will enhances their well known effect on the health by removing some of polar substances which interferes with the action of the vegetable oils active ingredients (8). The aim of this study is to evaluate the effects of crude and washed sunflower oils on the serum lipid profile, liver cholesterol, tissue's lipid peroxidation (liver, heart and kidney) of the male rats in cases of experimental hyperlipidemia and hypercholesterolemia induced in the male rats by using of saturated fats and hydrogen peroxide.

\section{Materials and methods}

Hyperlipidemic and hypercholesterolemic diet: diet ingredients were supplied from local market in order to meet the rats nutritional and physiological requirements according to the AOAC (9). $0.26 \%$ of cholesterol powder (Merck Co., Germany) and 4.69\% saturated alcohol dissolved sheep tail fat were added to the other ingredients, diet was moitened with distilled water and formed in the shape of pellets dried in electrical oven at $55 \mathrm{C}^{\circ}$ then maintained in polyethylene bags in cool and dry place, moisture, ash and carbohydrates were determined according to Pearson (10), protein and crude lipid (ether extract) were determined according to American Nutrient Research Council (11) while the crude fibers were calculated from the difference between the sum of protein, lipid, carbohydrates, ash percentages and $100 \%$ (table 1).

Table (1) : dietary mixture and their ratios according to (11) and the chemical analysis based on dry weight.

\begin{tabular}{|l|r|l|r|}
\hline Diet composition & \multicolumn{2}{l|}{} \\
\hline Ingredients\% & & Nutrients \% \\
\hline Yellow corn & 47.04 & Crude fat & 7.13 \\
Wheat flower meal & 18.91 & Carbohydrates & 68.53 \\
Barley meal & 16.40 & Protein & 12.16 \\
Cake & 7.40 & Crude fibers & 6.58 \\
Sodium chloride & 1.40 & Ash & 5.58 \\
Calcium carbonate & 1.0 & Metabolic energy Kcal / $100 \mathrm{~g} * *$ & 380.98 \\
Sodium monophosphate & 1.40 & & \\
Inorganic elements & 1.50 & & \\
\hline Animal fat + cholesterol* & 4.95 & & \\
\hline
\end{tabular}

*Dietary total cholesterol was $0.67 \%$

**Metabolic energy $9 \mathrm{Kcal} / \mathrm{g}$ fat , 4 Kcal / g carbohydrates and protein . 
Crude sunflower oil extraction: sunflower seed's husks were removed manually, dehusk seeds milled with an electrical blender.

Moisture was determined according to Pearson (10), diethyl ether solvent was examined for the presence of peroxide (9), crude sunflower oil was extracted by using of soxhlet by using a mixture of diethylether and ethanol as 1:1 (9), solvents were evapurated on water bath then completed on hot plate $\left(45-50 \mathrm{C}^{\circ}\right)$

Sunflower crude oil ratio was calculated as following: $\%$ of Sunflower crude oil =

Weight of extracted oil / Weight of seed powder on dry matter $\times 100$

$$
=29.73 \% \text {. }
$$

Washing of extracted sunflower oil: the extracted oil was vigorously washed with warm water and benzene in a separatory funnel with continuous shaking in a water bath at $37 \mathrm{C}^{\circ}$ for 24 hours. The funnel settled overnight untill complete separation of the mixture for down watery and upper benzene layers which contains the distributed washed oil. Benzene layer was collected, benzene evapurated by using the rotary evaporator under vacuum. Dried oil weighted and maintained in a dark bottle at $7 \mathrm{C}^{\circ}$.

$\%$ of washed sunflower oil $=$

Weight of washed oil / Weight of crude oil $\times 100$

$$
=89.38 \%
$$

Chemical and physical properties of the crude and washed sunflower oils: peroxide value (meq/kg), iodine number, percentage of steroides and $\mathrm{pH}$ value were determined according to Pearson (10) in addition to certain chemical constituents of the both oils (total cholesterol and triglycerides) and physical property (specific gravity) for both oils were determined (9).

Hydrogen peroxide in drinking water: daily prepared fresh water containing $0.5 \%$ hydrogen peroxide $\left(\mathrm{H}_{2} \mathrm{O}_{2}\right)$ was used in drinking water of hypercholesterolemic rats (Ad libitum) (4).

Experimental design: thirty of adult albino male rats were divided into five groups and treated with hypercholesterolemic diet, in addition to hydrogen peroxide in drinking water for 30 days for induction of hypercholesterolemia as well as 15 days the period of treatment with sunflower oils as the following:

First group: control (hypercholesterolemia without treatment).

Second and third groups: treated with crude sunflower oil in a doses of 300 and $600 \mathrm{mg} / \mathrm{kg}$ body weight respectively by gaveging.

Fourth and fifth groups: treated with washed sunflower oil in a doses of 300 and $600 \mathrm{mg} / \mathrm{kg}$ body weight respectively by gaveging.

Quantitative determination of consumed oil fat and lipid absorption: 


\section{Consumed fat estimated as following:}

Consumed fat $(\mathrm{g})=$ consumed diet $(\mathrm{g}) \times$ diet's fat percentage

\section{Intestinal lipid absorption can be calculated as following:}

Intestinal lipid absorption $(\mathrm{g})=$ consumed dietary fat $(\mathrm{g})$ - elemenated feces lipid (g).

Blood specimens collection: blood specimens were collected from retroocular vein by using capillary tubes. After coagulation blood samples were centrifuged (3000 RPM) for $15 \mathrm{~min}$, then serum was collected and maintained in deep freezing.

Lipid profile determination: total lipid (TL mg/ $100 \mathrm{ml}$ ) was determined according to Toro and Ackermann (12) by oxidizing the lipid content in the sample then adding phosphovanilline reagent whereas total cholesterol (TC) and triglycerides (TG) were determined $(\mathrm{mg} / 100 \mathrm{ml})$ by using determination kits from Syrbio reagents Co. Depending on enzymatic method, Low density lipoproteins (LDL-c) and high density lipoproteins (HDL-c) $(\mathrm{mg} / 100 \mathrm{ml})$ determined by specific kits from Syrbio reagents Co. which depends on the precipitation of them and then estimation was done by using of cholesterol kit .

Calculation of very low density lipoproteins and phospholipids: very low density lipoproteins (VLDL-c $\mathrm{mg} / 100 \mathrm{ml}$ ) calculated according to Tietz (13) VLDL-c $(\mathrm{mg} / 100 \mathrm{ml})=$ Triglycerides $/ 5$

Phospholipids $($ PL mg/ $100 \mathrm{ml})=($ Total cholesterol $\times 0.89)+68(\mathbf{1 3})$.

Tissue sampling: rats were sacrificed at the $15^{\text {th }}$ day and the organs (liver, kidney and heart) were separated, washed with cold normal saline and maintained in deep freezing.

Determination of malondialdehyde in the tissues: malondialdehyde was determined according to Gilbert (14) by reacting the MDA content in the sample with thiobarbituric acid which gives a colored complex.

Determination of total cholesterol in the liver: liver total cholesterol determined according to Folk, Morita $(\mathbf{1 5 , 1 6 )}$ by dissolving the cholesterol in the sample with chloroform and ether then determinated by the specific kit .

Statistic: all data were analyzed for the mean characters with the analysis of variance and Duncan multiple test range for the standard error differences according to Steel and Torrie (17).

\section{Results}

The washing process led to a decrease in the iodine number, peroxide value, specific gravity and the percentage of steroids, $\mathrm{pH}$ was elevated in the 
washed oil and the highly oil contents of total cholesterol and triglycerides was slightly affected by the process of washing (Table 2).

Table (2): Chemical and physical properties of crude and washed sunflower oils. $\mathbf{T C}=$ Total cholesterol, $\mathbf{T G}=$ Triglycerides.

\begin{tabular}{|l|l|l|l|l|l|l|l|}
\hline $\begin{array}{l}\text { Sunflower } \\
\text { extract }\end{array}$ & $\begin{array}{l}\text { Iodine } \\
\text { number }\end{array}$ & $\begin{array}{l}\text { Peroxide } \\
\text { value mg/ } \\
\mathbf{k g}\end{array}$ & $\begin{array}{l}\text { Specific } \\
\text { gravity }\end{array}$ & $\begin{array}{l}\text { Steroides } \\
\mathbf{\%}\end{array}$ & $\mathbf{p H}$ & $\begin{array}{l}\text { TC } \\
\mathbf{g} / \mathbf{1 0 0 g}\end{array}$ & $\begin{array}{l}\text { TG } \\
\mathbf{g} / \mathbf{1 0 0 g}\end{array}$ \\
\hline $\begin{array}{l}\text { Crude } \\
\text { sunflower oil }\end{array}$ & 122.40 & 7.10 & 1.23 & 41.60 & 5.30 & 50.71 & 182.0 \\
\hline $\begin{array}{l}\text { Washed } \\
\text { sunflower oil }\end{array}$ & 102.0 & 5.50 & 0.93 & 39.41 & 7.30 & 53.91 & 180.61 \\
\hline
\end{tabular}

Table (3) showed that there was a significant decrease in the rat body weight gain, diet intake and dietary fat consumption in the groups treated with the dose $600 \mathrm{mg} / \mathrm{kg}$ body weight of both oils while the weight gain was increased in the group treated with the dose $300 \mathrm{mg} / \mathrm{kg}$ body weight of crude oil which was higher than that value of control group, diet intake and dietary fat consumption were less than that values of the control especially with the treatment with crude oil $300 \mathrm{mg} / \mathrm{kg}$ body weight but there was no significant difference between the control and the treatment with washed oil $300 \mathrm{mg} / \mathrm{kg}$ body weight.

The weight of feces was the same in the control and group treated with sunflower oils $300 \mathrm{mg} / \mathrm{kg}$ body weight but it was elevated by the treatment with $600 \mathrm{mg} / \mathrm{kg}$ body weight of both two trails of oils, also there was no significant difference in the fecal fat between all groups except the group treated with the washed oil $600 \mathrm{mg} / \mathrm{kg}$ body weight.

There was no significant difference $(p>0.05)$ in the intestinal fat absorption between the groups treated with the washed oil of both doses and control group, the least significant $(\mathrm{p} \leq 0.05)$ value of the intestinal fat absorption was seen in the group treated with the crude oil $600 \mathrm{mg} / \mathrm{kg}$ body weight which was not significant with the group treated with the crude oil $300 \mathrm{mg} / \mathrm{kg}$ body weight. 
Table (3): Effect of crude and washed sunflower oil on the nutritional status in the male rats with induced hypercholesterolemia by saturated animal fats, cholesterol and hydrogen peroxide (mean \pm S.E.).

\begin{tabular}{|c|c|c|c|c|c|c|c|}
\hline \multirow{2}{*}{ Rat groups } & \multicolumn{2}{|c|}{ Body weight (g) } & \multicolumn{2}{c|}{ Ingested diet } & \multicolumn{2}{c|}{ Eliminated feces } \\
\cline { 2 - 7 } & $\begin{array}{c}\text { Primary } \\
\text { weight }\end{array}$ & Gain & weight $(\mathrm{g})$ & Fat content mg & weight (g) & $\begin{array}{c}\text { Fat content } \\
\mathrm{mg}\end{array}$ & $\begin{array}{c}\text { Fabsorption } \\
\text { abs }\end{array}$ \\
\hline Control & $204.27 \pm 4.94 \mathbf{a}$ & $22.59 \pm 1.41 \mathbf{b}$ & $153.70 \pm 5.45 \mathbf{a}$ & $10.96 \pm 0.38 \mathbf{a}$ & $46.20 \pm 1.55 \mathbf{b}$ & $6.56 \pm 0.16 \mathbf{a}$ & $4.42 \pm 0.42 \mathbf{a}$ \\
\hline $\begin{array}{c}\text { Crude } \\
\text { sunflower oil } \\
300 \mathrm{mg} / \mathrm{kg}\end{array}$ & $209.09 \pm 3.12 \mathbf{a}$ & $43.56 \pm 4.18 \mathbf{a}$ & $116.70 \pm 1.87 \mathbf{b c}$ & $8.32 \pm 1.33 \mathbf{b c}$ & $45.05 \pm 1.27 \mathbf{b}$ & $6.57 \pm 0.11 \mathbf{a}$ & $1.75 \pm 0.17 \mathbf{b c}$ \\
\hline $\begin{array}{c}\text { Crude } \\
\text { sunflower oil } \\
600 \mathrm{mg} / \mathrm{kg}\end{array}$ & $213.58 \pm 5.14 \mathbf{a}$ & $30.47 \pm 0.86 \mathbf{b}$ & $98.50 \pm 1.79 \mathbf{c}$ & $7.02 \pm 0.12 \mathbf{c}$ & $51.95 \pm 0.99 \mathbf{a}$ & $6.25 \pm 0.19 \mathbf{a}$ & $0.81 \pm 0.25 \mathbf{c}$ \\
\hline $\begin{array}{c}\text { Washed } \\
\text { sunflower oil } \\
300 \mathrm{mg} / \mathrm{kg}\end{array}$ & $207.00 \pm 2.79 \mathbf{a}$ & $42.90 \pm 6.24 \mathbf{a}$ & $135.62 \pm 12.06 \mathbf{a b}$ & $9.67 \pm 0.86 \mathbf{a b}$ & $48.73 \pm 2.14 \mathbf{a b}$ & $6.20 \pm 0.32 \mathbf{a}$ & $3.47 \pm 0.81 \mathbf{a b}$ \\
\hline $\begin{array}{c}\text { Washed } \\
\text { sunflower oil } \\
600 \mathrm{mg} / \mathrm{kg}\end{array}$ & $204.68 \pm 5.37 \mathbf{a}$ & $26.20 \pm 3.78 \mathbf{b}$ & $97.44 \pm 8.15 \mathbf{c}$ & $6.95 \pm 0.58 \mathbf{c}$ & $53.14 \pm 1.85 \mathbf{a}$ & $4.85 \pm 0.50 \mathbf{b}$ & $3.10 \pm 1.08 \mathbf{a b}$ \\
\hline
\end{tabular}

* The different letters in the same column indicate that there were a significant differences values $(P \leq 0.05)$. All the rat groups feed animal fats, cholesterol in the diet and offered hydrogen peroxide in drinking water.(n=6) 
Figure (1) showed that the highly significant $(\mathrm{p} \leq 0.05)$ decrease in the total lipids (TL) and triglycerides (TG) was seen in the groups treated with the dose $300 \mathrm{mg} / \mathrm{kg}$ body weight of both trail oils, while the high significant decrease in the phospholipids (PL) was seen in the groups treated with the washed oil and crude oil $300 \mathrm{mg} / \mathrm{kg}$ body weight, but the treatment with crude oil $600 \mathrm{mg} / \mathrm{kg}$ body weight led to significant $(\mathrm{p} \leq 0.05)$ increase in the PL value in comparison with the other treatments which still significantly less than the value of the control group.

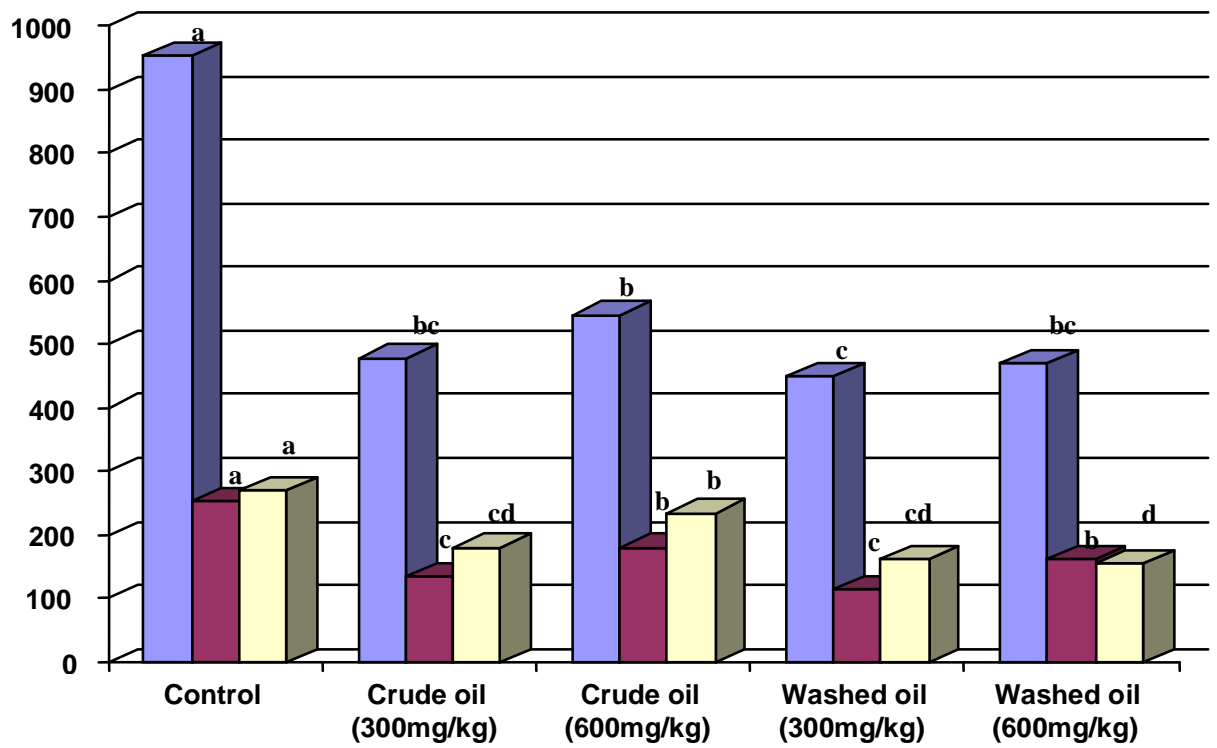

$\square \mathrm{TL}(\mathrm{mg} / 100 \mathrm{ml})$ $\square T G(\mathrm{mg} / 100 \mathrm{ml})$ $\square \mathrm{PL}(\mathrm{mg} / 100 \mathrm{ml})$

Fig (1) : Effect of crude and washed sunflower oil on total lipids, triglycerides, and phospholipids. $n=6$.

Figure (2) refers to the high significant $(p \leq 0.05)$ difference in the serum total cholesterol (TC) was for the groups treated with the both doses of washed oil, in addition to the treatment with crude oil $300 \mathrm{mg} / \mathrm{kg}$ body weight, the group treated with the crude oil $600 \mathrm{mg} / \mathrm{kg}$ body weight was higher in the TC than the other treated groups but still significantly $(\mathrm{p} \leq 0.05)$ under the value of the control group.

Liver total cholesterol was decreased in the groups treated with the crude oil as well as washed oil $300 \mathrm{mg} / \mathrm{kg}$ body weight, the group of washed oil $600 \mathrm{mg} / \mathrm{kg}$ body weight did not differ from the dose $300 \mathrm{mg} / \mathrm{kg}$ body weight of the two trails of sunflower oils but it considered to be declined in comparison with the control group. 


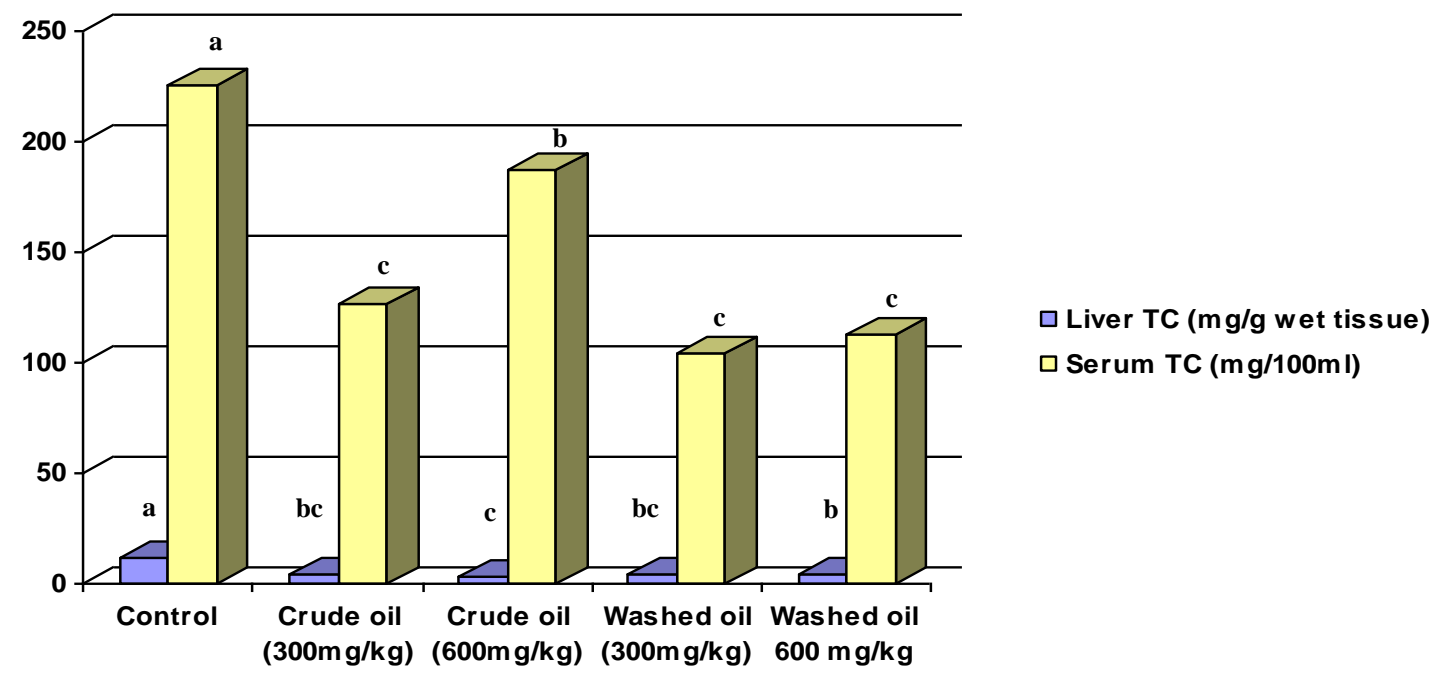

Fig (2) : Effect of crude and washed sunflower oil on serum and liver total cholesterol , $\mathrm{n}=\mathbf{6}$.

Figure (3) show a decrease in the LDL-c in the groups treated with the two doses of the washed oil in addition to the treatment with the crude oil $300 \mathrm{mg} / \mathrm{kg}$ body weight which did not differ from the group treated with the dose of $600 \mathrm{mg} / \mathrm{kg}$ body weight of the same oil, but the last group value of LDL-c is significantly decreased in comparison with the control, The very low density lipoproteins (VLDL-c), was highly decreased in the groups treated with the dose $300 \mathrm{mg} / \mathrm{kg}$ body weight for two trails of oils but the decreased value was still less significant $(p \leq 0.05)$ than the treatment with the dose $600 \mathrm{mg} / \mathrm{kg}$ body weight in comparison with the control group. High density lipoproteins (HDL-c) value was elevated in all groups treated with sunflower oils in comparision with untreated control.

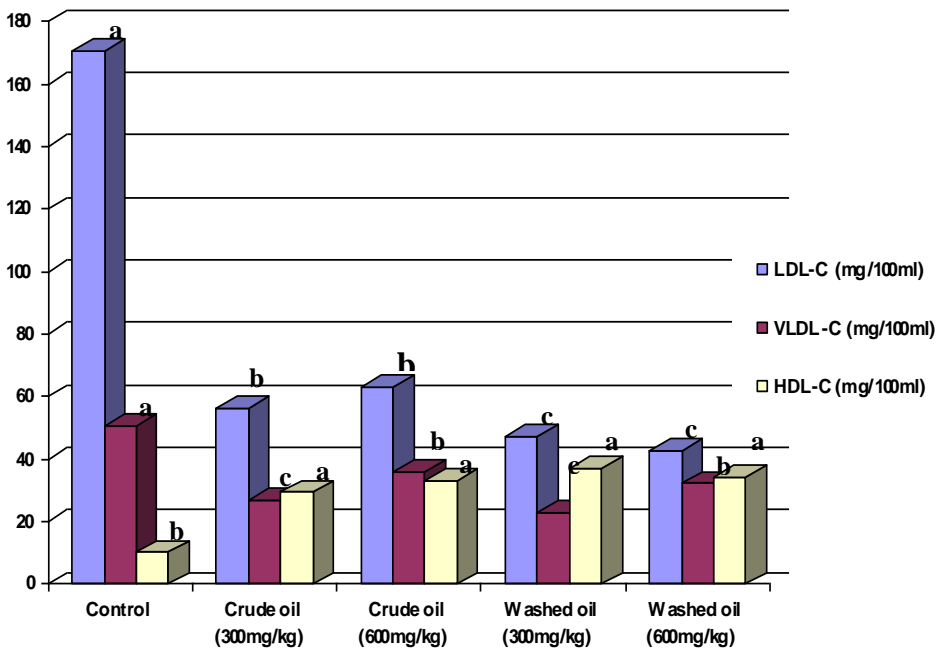

Fig (3) : Effect of crude and washed sunflower oil on lipoproteins concentration, $n=6$. 
Table (4) showed that the more significant $(\mathrm{p} \leq 0.05)$ decline in the malondialdehyde (MDA) content in the liver seen in the group treated with washed oil $300 \mathrm{mg} / \mathrm{kg}$ body weight which has a greater rate of decline than the group which treated with crude oil in the same dose $(300 \mathrm{mg} / \mathrm{kg}$ body weight), while the MDA content is declined more significantly in the groups of crude oil $600 \mathrm{mg} / \mathrm{kg}$ body weight and washed oil $300 \mathrm{mg} / \mathrm{kg}$ body weight. In the kidneys the treatment with crude and washed sunflower oil of both doses caused a significant $(\mathrm{p} \leq 0.05)$ decrease in the MDA content of the four treated groups in the same manner in comparison with control.

Table(4): Effect of crude and washed sunflower oil on the malondialdehyde of liver, heart and kidneys in the adult male rats with induced hypercholesterolemia by saturated animal fats, cholesterol and hydrogen peroxide.

\begin{tabular}{||c|c|c|c||}
\hline \multirow{2}{*}{ Rat groups } & \multicolumn{3}{|c||}{ Malondialdehyde nmol/g wet tissue } \\
\cline { 2 - 4 } & liver & heart & kidneys \\
\hline Control & $836.31 \pm 12.18 \mathbf{a}$ & $806.01 \pm 18.21 \mathbf{a}$ & $801.77 \pm 24.35 \mathbf{a}$ \\
\hline $\begin{array}{c}\text { Crude sunflower } \\
\text { oil 300mg/kg }\end{array}$ & $403.96 \pm 27.85 \mathbf{c}$ & $562.94 \pm 29.44 \mathbf{b}$ & $476.27 \pm 32.38 \mathbf{b}$ \\
\hline $\begin{array}{c}\text { Crude sunflower } \\
\text { oil 600mg/kg }\end{array}$ & $621.56 \pm 17.25 \mathbf{b}$ & $291.31 \pm 16.71 \mathbf{c}$ & $404.73 \pm 20.91 \mathbf{b}$ \\
\hline $\begin{array}{c}\text { Washed sunflower } \\
\text { oil 300mg/kg }\end{array}$ & $290.37 \pm 15.39 \mathbf{d}$ & $355.66 \pm 9.19 \mathbf{c}$ & $404.06 \pm 21.89 \mathbf{b}$ \\
\hline $\begin{array}{c}\text { Washed sunflower } \\
\text { oil 600mg/kg }\end{array}$ & $562.25 \pm 34.60 \mathbf{b}$ & $552.93 \pm 34.80 \mathbf{b}$ & $451.58 \pm 35.25 \mathbf{b}$ \\
\hline
\end{tabular}

The different letters in the same column indicate that there were a significant differences values $(P \leq 0.05)$. All the rat groups feed animal fats, cholesterol in the diet and offered hydrogen peroxide in drinking water. $(n=6),($ mean \pm S.E.

\section{Discussion}

Results in table (2) refers to the washing process in causing a decrease in the iodine number that's means some of unsaturated fatty acids UFAs may removed by the washing solution, the international values of iodine number range between (88-135) (3). there was a decrease in the peroxide value caused by the washing process but this value remained over the international values (3). The specific gravity ( $\mathrm{Sp}$. Gr.) of the crude oil was higher than the reference value but washing normalized this value and increased $\mathrm{pH}$ value. The other characters (steroids, total cholesterol TC, triglycerides TG) did not affected with the washing process because of non polar characteristics of these compounds that did not dissolved in the polar phase (warm water). The decrease in iodine number means a decrease in the level of UFAs which was at the acidic state therefore $\mathrm{pH}$ value raised toward the alkaline state. 
Results in table (3) showed that, the decrease in the rats body weight gain in groups treated with crude and washed oils of $600 \mathrm{mg} / \mathrm{kg}$ body weight, was resulted from the decrease in the dietary consumption which may be resulted from some interactions of oils with metabolic status especially in the high dose of sunflower oil whereas the decrease in the fat absorption which seen by the treatment with crude oil $600 \mathrm{mg} / \mathrm{kg}$ body weight may resulted from the high amount of fecal fat in this group (4) while the washed oil $600 \mathrm{mg} / \mathrm{kg}$ body weight. showed a less amount of fecal fat with relatively high fat absorption which thought to be resulted from the increase rate of fat intestinal absorption by the treatment with washed oil which considered to be more pure and show it's effect in high doses.

Figure (1) showed that the decrease in the total lipids (TL) and triglycerides (TG) in the rat groups treated with washed and crude oils 300 $\mathrm{mg} / \mathrm{kg}$ body weight, was resulted from the high content of PUFAs (3) and (4) while the washed oil in the high dose $(600 \mathrm{mg} / \mathrm{kg}$ body weight.) caused the same effect of crude oil. This may be due to the relatively high dose administration but the greater decrease in the phospholipids (PL) in this group was resulted from the high relationship between PL and total cholesterol (TC) (4).

Figure (2) referred to the washing process success in decreasing TC even in the dose of $600 \mathrm{mg} / \mathrm{kg}$ body weight which was the higher in the group of crude oil but it was lower than the control, it is mostly resulted from the ability of the washing process to remove some materials which it may make an impairment to the cholesterol metabolism such as lectin (4).

The action of sunflower oil on TC was resulted from it's content of PUFA and MUFA (18). In addition to the high amount of the Phytosterols (approx. 40\%) (19) present in sunflower oil and the increase in the fecal excretion of steroids and bile acids which utilizes high amount of cholesterol (20) as well as to the action of sunflower oil in the modulating of intestinal fat absorption (4) and increasing insulin level (21). Washing process was not able to decrease liver TC in the same manner compared with the crude oil. The ability of Sunflower oil to decrease liver TC due to it's content of tocotrienols which is known to inhibit 3- hydroxy 3- methyl glutaryl CoA (HMG-CoA) reductase (a rate limiting enzyme in cholesterol biosynthesis) in the liver resulting in hypocholesterolemia and decrease liver cholesterol (20).

Figure (3) referred to the decrease in the low density lipoproteins (LDL-c) in the rat groups treated with washed oils was similar levels to those of TC, this decrease is related to TC which is $70 \%$ of it is carried in blood by LDL-c particles (4). The treatment with sunflower oil will lead to 
increase the levels of LDL-c linoleinic acid (C18:3) which aids to normalize the metabolism of LDL-c (22). As considered with very low density lipoproteins (VLDL-c) and high density lipoproteins (HDL-c), there were no significant difference between the effect of crude and washed oils. The HDL-c was elevated in the same manner without relation to dose or the type of oil, this elevation was due to the elevation in the level of apoprotein A-4 (apo A-4) which is very sensitive to the increase in dietary lipids, independent on the degree of fatty acid saturation (23) which stimulate the HDL-c biosynthesis specially HDL-3 (21).

Results in table (4) showed that the treatment with washed oil $300 \mathrm{mg} /$ $\mathrm{kg}$ body weight which posses a peroxide value (5.50) less than that value of crude oil (7.10) caused the higher significant decrease in the malondialdehyde (MDA) concentration of the tissues especially in the liver which may lead to conclude that the washing process may cause a decrease in the ratio of the oxidized fatty acids in the oil which affect directly on the levels of lipid peroxides in the tissues and blood. The treatment with sunflower oil resulted a positive effect on the peroxidation lag time in addition to the linoleic acid (C18:2) present in the oil will enrich the LDL-c with this fatty acid which acts as antioxidant in the LDL-c particles (4).

In conclusion we can say that the washing process of crude sunflower oil did not affect serum TL, TG but positively affects the serum TC and lipoproteins in male rats and led to consume a larger amount of dietary fats without effect on serum TC in addition to the ability of the washing process to get rid of the portion of oxidized fatty acids in the oil and decreasing peroxidation products inside the cells.

\section{References}

1- Cabrini L., Barzanti V., Cipollone M., Fiorentini D., Grossi G., Tolomelli B., Zambonine L., and Landi L. J., Agric. Food Chem.; 49(12): 6026-6032 (2001).

2- Kaynak G., Erzos M. and Kara H., J. Colloid Interface Sci.; 280(1):131138 (2004).

3- Rudan-Tasic D. and Klofutar C., Acta. Chim. Slov.; 46(4):511-521 (1999).

4- Kallo M S. The effect of peanut and sunflower extracts on lipid profile in rats treated with hydrogen peroxide and animal fats. Msc. Thiesis, College of Veterinary Med. University of Mosul, Mosul- IRAQ, (2005).

5- Rudzinska M., Korczak J., Gramza A., Wasowicz E. and Dutta P.C., J. AOAC Int.; 87(2):499-504 (2004). 
6- Hamed S. F. and Mousa A., Journal of Applied Sciences Research; 2(1):27-33 (2006).

7- AL-Jaff S J. Effect of thyme extract alone and in combination with insulin on some biochemical parameters in normal and alloxan- induced diabetic rats. Msc. Thiesis, College of Veterinary Med. University of Mosul, Mosul- IRAQ, (2005).

8- Thomas F., J. Nutr.; 14: 23- 26 (2001).

9- Association of Official Analytical Chemistry AOAC. Officials Methods of Analysis. $8^{\text {th }}$ ed. Washington DC., 382- 514. (1980).

10- Pearson D. The Chemical Analysis of Foods. $7^{\text {th }}$ ed. Churchill Livingstone. Edinburgh, London and New York., 277.(1976).

11- American Nutrient Research Council. National Requirements of Laboratory Animals. National Academy of Sciences No. 10, Washington DC., 7- 27.( 1978).

12- Toro G. and Ackermann P. G. Practical Clinical Chemistry. Boston: Little Brown and Company, (1975).

13- Tietz N. W. Fundamentals of Clinical Chemistry. WB Saunders Company, (1982).

14- Gilbert H. S., Stump D. D., and Roth F. F., Analy. Biochem.; 137: 282286 (1984).

15- Folk J., Less M. and Sloanestanley G. H., J. Biochem.; 266: 497-509 (1957).

16- Morita T., Oh-hashi A., Takei K., Ikai M., Kasaoka S. and Kiniyama Sh. J. Nutr.; 127(3): 470- 477 (1997).

17- Steel R G D and Torrie J H. Principle and Procedures of Statistics. $2^{\text {nd }}$ ed. New York. Mc- Graw- Hill book Company, (1980).

18- Rodenas S., Rodriguez-Gil S., Merinero M. C. and Sanchez- Muniz F. J., J. Am. Coll. Nutr.; (5): 361- 369 ( 2005).

19- Wagner K. H., Tomasch R. and Elmadfa I.., Eur. J. Nutr.; 40(4):161167 ( 2001).

20- Sunitha T., Manorama R. and Rukmini C., Plants Food Hum Nutr.; 51(3):219- 230 ( 1997).

21- Gastonn D., Maunrtim SH. and Tioque A., J. Am. Coll. Nutr.; 20(4): 320- 326 ( 2001).

22- Carmena R., Ascaso J. F., Camego G., Varela G., Hurt-Camejo E., Ordovas J. M., Martinez-Valls J., Bergstom M. and Wallin B., Atherosclerosis; 125(2): 243- 255 ( 1996).

23- Navarro M. A., Acin S., Carnicer R., Guzman-Garcia M. A., ArbonesMainer J. M., Surra J. C., Cebrain J. A., Arnal C., Isabel B., Lopez-Bote C. J. and Osada J., Br. J. Nutr.; 92(5): 763- 769( 2004). 